\title{
EL CHE Y SU INTERTEXTO LITERARIO CERVANTINO: A PROPÓSITO DE ILADRAN CHE! DE CARLOS ALSINA
}

\author{
CHE AND HIS CERVANTINE LITERARY INTERTEXT: \\ ON THE SUBJECT OF LADRAN, CHE! BY CARLOS ALSINA
}

\author{
Jimena C. Trombetta \\ Universidad de Buenos Aires / CONICET \\ Argentina \\ jimenacecilia83@gmail.com
}

\begin{abstract}
Resumen: En el siguiente trabajo nos interesa analizar el intertexto de Don Quijote de la Mancha en el texto dramático de Carlos Alsina iLadran Che! El impulso inicial, que llevó al autor a contactar ambas figuras, surge de una serie de anécdotas que se pueden hallar en la propia vida de Ernesto Guevara, donde el propio Che se relaciona con el personaje cervantino. Para dicha empresa utilizaremos la biografía escrita por Pacho O'Donell y la propia obra teatral de Alsina. La intención es observar cómo se componen los personajes en la teatralidad de Alsina y qué tipo de imaginarios se construyen alrededor de la figura de Ernesto Guevara y nutren la obra iLadran Che! El análisis se sustenta en el concepto de héroe, en la noción de imaginarios sociales y en las definiciones de mito.
\end{abstract}

Palabras clave: Intertexto, Imaginario social, Historia, Ficción, Memoria.

Abstract: In the following work we are interested in analyzing the intertext of Don Quixote de la Mancha in the dramatic text Ladran, Che! by Carlos Alsina. The initial impulse, which led the author to contact both figures, arises from a series of anecdotes that can be found in the very life of Ernesto Guevara, where Che himself relates to Cervantes's character. For this task, we will use the biography by Pacho O'Donell and Alsina's own play. The intention is to observe how the characters are composed in the theatricality of Alsina and what kind of imaginary is built around the figure of Ernesto Guevara and nourish the work Ladran, Che! The analysis is based on the concept of hero, on the notion of social imaginary, and on the definitions of myth.

Keywords: Intertext, Social imaginary, History, Fiction, Memory.

Recibido: 29/09/2017. Aceptado: 27/03/2019. 


\section{Introducción}

Carlos Alsina es dramaturgo, director y docente de teatro nacido en San
Miguel de Tucumán en 1958. A lo largo de su carrera como artista de teatro y escritor ha elaborado 55 textos teatrales. Su historia como teatrista no se circunscribe a la productividad en Argentina en tanto que sus trabajos se han representado en Brasil, España, Italia, Suiza, Ecuador, Cuba, Albania, Puerto Rico, Estados Unidos, Francia, Uruguay, entre otros países. A su vez a dirigido una gran cantidad de montajes en Brasil, Italia y Suiza, y ha sido premiado por diversas entidades. Además de las obras que creó para niños y adolescentes, de las creaciones para teatro de títeres y de las historias más costumbristas, parte de su dramaturgia indagó sobre cuestiones vinculadas a la historia política del país. Entre esos títulos podemos mencionar Un brindis bajo el reloj (1982), que abordó la temática de la desaparición de personas durante la dictadura entre los años 1976-1983; Limpieza (1985), que narraba un hecho real: Antonio Domingo Bussi (Gobernador de Tucumán) había ordenado "limpiar" la ciudad de mendigos, deficientes mentales y dementes, a quienes se depositó sin contención social en las zonas fronterizas con Catamarca; El pañuelo (1991), que narra cómo una Madre de Plaza de Mayo transforma el reclamo de su hijo en la vivencia de 30 mil nuevos partos; El sueño inmóvil (1997), que mediante leyendas y mitos del noroeste argentino repiensa la historia argentina para observar los mecanismos del olvido y la memoria; y La guerra de la basura (1999), obra que observa cómo un genocida como Antonio Domingo Bussi retorna al poder en un marco democrático ${ }^{1}$. Las variaciones poéticas de las que Alsina se sirvió para narrar estas obras fueron desde el grotesco, a la farsa, el costumbrismo y la parodia. Desde todas estas poéticas Alsina puso el eje en relatar hechos de la historia reciente de Argentina para establecer un lazo con la necesidad de vincular al teatro desde el ejercicio de la memoria. En este marco se inscribe la obra de iLadran Che ${ }^{2}$ (1994), en tanto que

Para más información sobre Carlos Alsina visitar www.carlosalsina.com

${ }^{2}$ Alsina declaraba para la entrevista realizada para el presente artículo: "Poner la obra en Mendoza fue fruto de una casualidad. En 1993, si no me equivoco, se realizó la Fiesta Nacional del Teatro allí. Yo fui invitado como autor porque un elenco de Tucumán había escenificado otra obra mía “Esperando el lunes”. Y allí reencontré al Flaco Suárez y a Víctor Arrojo, a quienes había conocido en el Festival de Teatro Andino, realizado en Mendoza, si 
vino a cuestionar los discursos políticos y la devastación social que sucedía en el menemismo.

Por todos estos motivos, nos interesa analizar de qué modo se utilizó en aquella obra el intertexto de Don Quijote de la Mancha. Así observaremos cómo se relaciona el personaje cervantino con la vida de Ernesto Guevara a partir de una serie de anécdotas. La intención es mostrar cuáles son los paratextos de los que parte la obra. Para dicha tarea revisamos la biografía sobre el comandante escrita por Pacho O’Donell y los capítulos del Quijote que se pueden encontrar como intertextos en la obra de Alsina. Estos vínculos intertextuales entre el paratexto y el exotexto (Pérez Firmat, 1978) construyen desde nuestro punto de vista una composición de los personajes que nutren algunos imaginarios y mitos sobre el Che. Para observar qué tipo de mito y, por ende, qué tipo de héroe construye Alsina recurrimos al concepto de héroe propuesto por Joseph Campbell, también consideramos las definiciones de imaginarios sociales de Bronislaw Baczko y el estudio realizado por Perla Zayas de Lima sobre mito, que re-

no me equivoco en 1987 u 88, cuando fuimos con el elenco tucumano independiente "Teatro de Hoy" a representar mi obra teatral "Limpieza" (sobre los mendigos tucumanos que Bussi arrojó en Catamarca). Yo ya tenía "iLadran Che!" escrita. En uno de los almuerzos que compartimos durante el Festival, y escuchando el no resuelto conflicto entre las provincias y Buenos Aires, se me ocurrió proponerles fundar un proyecto llamado Teatro de las Provincias que, obviando el pasaje obligado por Buenos Aires, aunque no descartando el trabajo con colegas de esa procedencia, pusiera en contacto autores, directores y actores de diversas provincias con la construcción de espectáculos propios. Es decir, romper el plano inclinado y unilateral que suele llevar a los creadores a, necesariamente, converger en Bs. As. Establecer líneas de contacto entre las provincias y regiones argentinas que, como una nueva telaraña, no repita el esquema aéreo, ferroviario (que ahora ya no existe, prácticamente), comercial, de legitimación artística, etc. que siempre va hacia el puerto y allí se consolida y agiganta. Una utopía por la que aún hay que seguir luchando, me parece. Suárez y Arrojo compartieron mi propuesta. De pronto me iluminó la idea, al ver la figura del Flaco Suárez, que él podía hacer de Quijote, y al observar a Víctor, que podía hacer el Che. Además, mi texto era muy económico. No hacía falta una producción costosa y bastaba que yo pudiera sostenerme por el período de los ensayos en Mendoza con algunos seminarios y dábamos el puntapié inicial a ese otro proyecto más ambicioso. Tenía la obra en papel (no usaba computadora en esa época sino máquina de escribir) pues hacía poco que la había terminado y la estaba "cañoneando" críticamente en ese viaje a Mendoza. La leímos, les gustó y me sugirieron invitar a Vilma Rúpolo para hacer el personaje de Ella. La cuestión es que en aquella Fiesta de 1993 delineamos los ensayos y el estreno de la obra para el año siguiente. Yo volví a mis viajes y en el invierno de 1994 regresaba a Mendoza a ensayar y a poner en escena la obra. Se estrenó en el Teatro Independencia el 20 de agosto de 1994. Luego representó a Mendoza en la Fiesta Nacional de Teatro en Tucumán”. (Entrevista realizada el 13 de junio de 2017) 
pasa las posturas de Roland Barthes, Sergio Labourdette y Mircea Eliade, entre otros.

\section{¿Por qué ladraron?}

En primer lugar nos interesa preguntarnos el motivo por el cual Alsina, en 1994, estrena su obra en Mendoza con la finalidad de repensar la figura de Guevara en ese contexto histórico. Hay que tener en cuenta que el proceso de escritura estuvo enmarcado en el período de la posdictadura y bajo las políticas del período neoliberal. Esta etapa se caracterizó por la producción de textualidades que criticaban los discursos políticos debido a la reutilización de previos estandartes que se convirtieron en material de uso del capitalismo. En el caso de la imagen del Che ese perfil se instauró con una gran variedad de merchandising superando las fronteras latinoamericanas. En este nuevo contexto cultural se vislumbran los cambios estéticos en las búsquedas de Carlos Alsina. Jorge Dubatti sostiene que el teatro de Carlos Alsina se circunscribe a la diversidad de poéticas, a una idea de "dramaturgia sin dogmas”. Los años noventa, señala Dubatti, tuvieron la característica de que "nadie se jacta de poseer el discurso ideológico o estético más claro, de acuerdo con la caída de las grandes certezas" (Dubatti, s/f) ${ }^{3}$. $\mathrm{Y}$ agrega que se trataba de un teatro que le contestaba al neoliberalismo a través de la "destemporalización” y la "destotalización”, algo que se puede vislumbrar en iLadran Che! al transcurrir la acción en un no-lugar y al desarticular la idea de existencia de una verdad. Así se sucede otro punto interesante en la obra de Alsina, que Dubatti observa como propio de la época. Existen multiplicidad de formas para dar cuenta de una gran variedad de "imaginarios y visiones de mundo en perpetua modificación, de acuerdo a la percepción de la realidad” (Ídem). Así señalaba Alsina para una entrevista realizada para este artículo:

Escribí iLadran, Che! entre los años 1993-1994. La terminé en Brasil, en dónde vivía en algunos meses del año por esa época, trabajando allí y alternando mi quehacer entre Italia, Suiza y Argentina. El texto empezó

\footnotetext{
${ }^{3}$ Disponible en www.carlosalsina.com/estudioc.htm
} 
a nacer en mi cabeza luego de 1990 con la implementación de la política neoliberal menemista en la Argentina. Tal momento de auge del postmodernismo en el mundo (caída del Muro de Berlín en 1989, implosión de la URSS en 1991-1992, etc.) con la malintencionada postura de hacer creer que "la historia se había terminado", que el mundo "unipolar" era el vencedor incontrastable, fueron de "ayuda" para imaginar un texto teatral que tratara de refundar las utopías. (Entrevista realizada el 13 de junio de 2017)

De esta manera Alsina, mediante los recursos teatrales que señala Dubatti, construyó un texto que ponía en jaque la complejidad del mundo posmoderno: un Che Guevara al que le han hecho perder su peso histórico y que está dispuesto a escapar para reconstituirse no como figura mítica sino como pensamiento político.

\section{Don Quijote y Ernesto Guevara: puntos comunes desde la literatura y la historia}

La constitución del héroe guerrillero en el caso de la figura del Che se suele transfigurar en el héroe sobre el que Joseph Campbell señala una serie de características en su camino heroico. Este camino posee un primer paso que es la separación del mundo ordinario, la iniciación con una serie de viajes y el retorno con una serie de llegadas al mundo extraordinario. Esto se puede vislumbrar en la figura del Che con matices que varían entre considerarlo un hombre cercano al cristianismo, un líder romántico y hasta una estrella de rock. En este punto Carlos Alsina intenta huir de ese lugar de héroe romántico idealizado. El autor hace dialogar ${ }^{4}$ al Che Guevara con Don Quijote: un héroe con un camino similar, en términos de Joseph Campbell, pero que Cervantes se ocupó de parodiar en su novela Don Quijote de la Mancha publicada originalmente en 1615. El tipo de heroísmo que construyó Cervantes, tal como señala Joaquín Casalduero (1981), es

\footnotetext{
${ }^{4}$ Cuando exponemos que ambos personajes dialogan, partimos de la base que en ese acto se produce lo que Bajtin define como dialoguismo y que Julia Kristeva menciona como intertextualidad, es decir ese "diálogo» que se produce en el interior de un enunciado, discurso o texto entre el Sujeto de la enunciación y el Sujeto del enunciado (Kristeva, 1969: 206).
} 
uno burlesco sobre todo en lo caballeresco y en lo amoroso, dos puntos que Alsina retoma en la propuesta de iLadran Che! Explica Casalduero:

Don Quijote se dirige a Dulcinea, Sancho a la ínsula-, son semejantes, son aspectos distintos del mismo mundo mental. Por eso Sancho puede estar solo, solo en la ínsula, solo cuando muera Don Quijote. Dulcinea y la ínsula son dos aspectos distintos de la mente de Don Quijote. El gracioso no existe sin el caballero; si hacemos desaparecer a este, la acción, la palabra del gracioso son incomprensibles. Por eso, en el primer Barroco las figuras cómicas son siempre cómicas y no pueden dejar de serlo. El gracioso nunca es serio, pero no siempre es cómico. A veces es el gracioso el que con su gesto y tono propios nos hace penetrar en el mundo de la culpa o del castigo, es él quien puede expresar toda la bajeza del cuerpo y al mismo tiempo presentarnos la realidad del alma. (Casalduero, 1981: 16)

Así como Miguel de Cervantes parodia las historias caballerescas, Alsina parodia toda la construcción mítica alrededor de Ernesto Guevara incorporándolo al mundo Cervantino. El personaje del Che Guevara en el texto dramático mezcla su lenguaje con el que produce Don Quijote. Alsina explicaba que había utilizado fragmentos de la novela, por ejemplo el debate entre las armas y las letras que es cita textual de la novela y algunas expresiones de los odres de vino. A su vez, en relación al Che, el autor retomaba textos que hacían referencia a la imposibilidad de visitar la Isla de Pascua provenientes del diario Notas de viaje. Diarios en motocicleta (2007). A través del testimonio de Alsina y del estudio de la obra podemos ubicar el vínculo entre el exotexto y los paratextos (Pérez Firmat, 1978) que utilizó el autor para construir la dramaturgia. Lo que nos interesa es ver cómo estos intertextos establecen un diálogo directo y abierto entre ambos personajes. Este diálogo, en boca del personaje histórico Che Guevara y del personaje de ficción Don Quijote, provoca nuevas lecturas sobres los episodios que se retoman de los textos originales. Por ejemplo, el intertexto con el capítulo XXXVIII del Quijote I se desarrolla durante algunos apartados dentro de iLadran Che! En este capítulo Cervantes elabora un breve ensayo en el que Don Quijote expresa una comparación crítica entre la importancia de las armas y de las letras, dando a esas primeras un mayor peso. Casi como una discusión entre el personaje ficticio y su creador se establecen muchos puntos comparativos que, con ironía y comicidad, Alsi- 
na traslada al diálogo con el Che. Allí, Don Quijote expresa nuevamente su postura sobre las armas, vehículo para lograr la paz según este personaje; y declara lo mal que le cae Cervantes como letrado. El diálogo se extiende al Che, personaje complejo también por su rol de guerrillero y por su legado escrito, quien acuerda con Quijote que sufre más el soldado que el escritor. El otro ejemplo que mencionaba Alsina sobre la imposibilidad de visitar la Isla de Pascua (una isla que se encuentra sobre el Océano Pacífico frente a Valparaíso, Chile) es trabajado en la obra mediante una cita textual ${ }^{5}$ y una serie de alusiones a lo narrado en el diario Notas de viaje. Diarios en motocicleta. Lo que es interesante es ver que en ese fragmento, el propio Guevara da cuenta en su diario de un contenido imaginario sobre la Isla, lo que le agrega cierta ficción al propio relato del Che. Este mundo fantástico es el que Alsina traslada al diálogo con Don Quijote, y la Isla de Pascua pasa a ser un destino para escapar de allí y seguir viajando.

En este punto es pertinente rescatar las palabras de Alsina para este artículo, en las que menciona el vínculo entre los dos personajes:

Como ve, el proceso de escritura de la obra, que junta a estos dos personajes (uno real y otro de ficción) viene de lejos, aunque haya "aparecido" en Brasil en 1993, condicionado por el clima adverso que, para mi concepción y sentir del mundo, se había instaurado. En la etapa de "escritura interior” (o sea: a la de estar atento al retorno de algunas imágenes) los veía juntos y encerrados en algún lugar planificando una fuga. Y aparecía una figura que lo impedía. Fue entonces que se comenzaron a unir elementos: la fuga, la resistencia para no perder la utopía (pienso que ambos personajes son símbolos de la utopía: una idealista, otra material y concreta), apareció la moto del Che de su viaje por Latinoamérica (y el Rocinante del Quijote), la figura de Ella, como un personaje simbólico que, satisfaciendo los deseos de lo que fueron ambos, de la repetición de sus mitos, los anestesia y los hace impotentes. Se ve que, adentro mío, me preguntaba si no era conveniente resistir apelando a nuevas armas ya que el mundo y el capitalismo había logrado una "victoria" que, sabía, no era tal, pero que nos colocaba frente a nuevos desafíos. Allí cerró todo y encontré el final. La moto arranca (o Rocinante cabalga) cuando los personajes se despojan de lo que les sirvió en el pasado y se

5 “(...) las mujeres ideales, la comida ideal, el trabajo ideal (...)" (Guevara, 2012, 64). Esta cita del libro del Che es prácticamente textual en la obra de Alsina, solo se altera el orden de la enumeración. 
animan a aventurar otras armas para pelear por un mundo mejor. Esto no significaba, para mí, que la experiencia histórica del Che, o el mundo de la caballería en el Quijote, debía ser olvidada. No. Simplemente me preguntaba: ¿Con estas experiencias frente al "mundo unipolar" y al "triunfo planetario" del capitalismo, qué armas oponer? (Entrevista realizada el 13 de junio de 2017)

Ambos personajes articulan recuerdos a través de las cartas de amistades que los siguieron en sus aventuras. Se trata de Camilo Cienfuegos y del propio Sancho Panza. Sancho escribe desde su mundo al que gobierna, imaginario y ficcional; y Camilo escribe poéticamente perdido entre las nubes. El Che y Don Quijote se miran con complicidad elevando un mensaje irónico en el que el discurso revolucionario ha sido el que ha triunfado. Ambos desde un espacio no definido y mediante sus gestos dan cuenta que el mundo mental que comparten con sus amistades fue devastado por el tiempo presente, por el neoliberalismo de los noventa. En este punto sucede lo que señala Casalduero: las cartas poseen elementos cómicos porque terminan de conformar el carácter de guerrillero del Che y de caballero de Don Quijote en tanto que no les queda otra que intentar mantener la farsa del supuesto triunfo de la revolución. Dicen el discurso incómodamente.

Lo que se parodia, justamente, es esa manera de recordar a Guevara muchas veces plasmada en las biografías. Por ejemplo, Pacho O’Donell recupera un testimonio que habla del Che como “(...) un líder revolucionario, un idealista, un romántico. (...) debería servir para que todos tengamos su vida y su pensamiento como referencia de un líder romántico que nunca vaciló en sus ideales. Sin miedo y sin tacha, su vida es una parábola perfecta, sin objeciones" (2012, 43). Así la nostalgia de la revolución, parodiada, es uno de los puntos que comienza a definir los personajes, más allá que Alsina no narre en su obra la historia familiar del Che. iLadran Che! apunta a ofrecer algunos caracteres que remiten al trabajo de Cervantes y los hace discutir con dos épocas: la del propio Guevara y la contemporánea a la obra de Alsina.

La obra de Alsina revisita desde la comedia la idea del amor, aunque a diferencia de la historia de Cervantes lo desliga del cristianismo. En ese punto Alsina rompe con la idea de Guevara vinculado al cristianismo, que 
imaginariamente se lo constituyó en algunos testimonios históricos. Así, Alsina cuestiona el mundo sobrenatural con ese supuesto ascenso imaginario que en Guevara fue anclado a partir de la circulación de algunas fotografías: la de Freddy Alborta y la de Alberto Korda. Recordemos que las imágenes habían recorrido el mundo a través de la prensa brindando una lectura mítica sobre el cuerpo de Guevara. Alrededor de la foto de Korda circuló y se conformó el vivo estandarte del héroe guerrillero. En cuanto a la foto de Alborta existieron un sinfín de lecturas populares que lo ubicaron al lado de Cristo. Bronislaw Baczko explica como:

Los "guardianes" del imaginario social también son guardianes de lo sagrado. El margen de libertad y de innovación en la producción de representaciones colectivas, sobre todo imaginarios sociales, es particularmente restringido. El simbolismo del orden social, de la dominación y de la sumisión, de las jerarquías y de los privilegios, etc., se caracteriza por una remarcable rigidez. Las técnicas de manejo de esos símbolos se confunden con la práctica de los ritos que reproducen el fondo mítico y son técnicas tanto del cuerpo como del arte y del lenguaje”. (2005: 18)

Entonces, la figura del Che Guevara se desarrolla míticamente en el ámbito de los imaginarios sociales como caballero andante. Alsina, en su obra, asocia a Guevara a su pensamiento de hombre nuevo y desde allí lo vincula con el amor a toda la humanidad. Sin embargo, a este movimiento no se le quitan los recursos ficcionales que ofrece la obra, en tanto que el propio Quijote, como personaje de literatura, llevará ese discurso al mundo de los libros de caballería.

DON QUIJOTE: Ese "hombre nuevo" de quien tanto hablas, ya existió en los libros de caballería. Es el Caballero Andante, para quien están guardados los peligros, las grandes hazañas, los valerosos hechos. Es el desfacedor de entuertos que...

CHE: iSí, claro!...el "desfacedor" de entuertos que ingenuamente creyó que sólo bastaba con hacer prometer al patrón de no azotar más a su criado para que dieras vuelta la "esquina" y todo volviera a la normalidad: los azotes al muchacho. Te lo recuerdo, gallego, Capítulo IV del primer volumen.

DON QUIJOTE: Y yo te recuerdo que más adelante, cuando me enteré de aquella lealtad, me propuse castigar a ese villano, pero no pude, 
porque estaba comprometido en otra aventura, y cuando los Caballeros Andantes... ${ }^{6}$ (Alsina, 2012: 3)

Dentro de los mitos que descompone Alsina se encuentra el juego que propone con la metamorfosis de médico-guerrillero-estadista-guerrillero. Para esto no se priva de marcar una anécdota muy conocida, aquella en la que Guevara abandona el botiquín de primeros auxilios por la caja de municiones. Así lo señala Alsina ${ }^{7}$ en una didascalia:

(El Che, en la confusión, no sabe si tomar la mochila-botiquín o la caja de municiones. Opta por esta última. Corre con ella. Un disparo lo golpea. Cae. Don Quijote, que trataba, absurdamente, de cubrirse de los disparos atrás de la lanza, reacciona y lo ayuda. Lo alza y lo coloca en un lugar "seguro". El ruido de los disparos como así también los aviones y los helicópteros se van alejando.) (Alsina, 2012: 5)

\footnotetext{
${ }^{6}$ En el capítulo IV Don Quijote encuentra un muchacho llamado Andrés siendo azotado por su amo Juan Haldudo, un rico que no respondía a los códigos de la caballería. Quijote como desfacedor de agravios en ese acto le ordena que deje de pegarle a Andrés y le pague lo que le debe. Juan le da la razón pero una vez que Don Quijote se retira, supuestamente triunfante, sigue azotando a Andrés hasta dejarlo medio muerto.

${ }^{7}$ A su vez Alsina para la entrevista realizada para el presente artículo explicaba el vínculo que lo impulsaba a escribir sobre Guevara: "Mi formación intelectual y política, como se imaginará por mi edad, tiene que ver con los años 70 en los cuales la figura del Che y de su muerte fue un faro para miles de jóvenes. Yo no sólo había leído mucho sobre el Che, sobre su vida, sino que, además, fui compañero, en los años 1970-71-72, de su sobrino directo, hijo de Ana María Guevara, hermana del Che, y del arquitecto Chávez, quienes vivían en Tucumán en esos años. Fui amigo de Santiago y frecuentaba su casa, con lo cual tuve acceso directo a algunos aspectos de la vida del Che como cartas, fotos y otros detalles familiares de los Guevara. A pesar de mi juventud (era un niño-adolescente) viví el clima de la época y empecé a militar políticamente ya en esos años. La situación en Tucumán era explosiva y, de un día para el otro, Santiago no fue más al colegio. No nos saludamos ni nos avisó que su familia había decidido emigrar. Volví a ver a Santiago Chávez 26 años después en La Habana cuando fuimos con el elenco de "El Sueño Inmóvil", ganadora del Premio Casa de las Américas, al Festival Internacional de Teatro. E hicimos un asado con toda la familia Guevara en la casa de la segunda esposa del papá del Che. En fin, le cuento estos detalles porque mi aproximación al Che no fue solo política, digamos. Fue indirectamente personal a través de, estos, sus parientes. Como le decía, había leído, además mucho sobre las ideas y la vida del Che. Desde sus teorías económicas de un dirigente ya formado políticamente hasta sus diarios de viajes, o sea el Che juvenil. Me "puse de su lado" en el interesante debate cubano entre el "estímulo moral" (que él sostenía) o el "estímulo económico" (que sostenía el estalinismo y se practicaba en la Urss.) También compartí su crítica al aliniamento con el mundo estalinista aunque no la teoría del foco armado a la que él adhería. Creo que son pocas las biografías del Che que no leí. Esto a través de los años. El Che fue entrando desde adolescente en mí y cuando me hice adulto, a través de sus escritos (no sé cuál no leí)". (Entrevista realizada el 13 de junio de 2017)
} 
Alsina recorre también otro punto característico de ambos personajes. Los objetos que utiliza en la obra son reflejo e ícono de la identidad de los personajes. “"La tragedia de la repetición» la llama Alsina, repetición de las imágenes que cada uno de estos dos personajes ha construido a través de la literatura, en el caso del Quijote, y a través de su propia vida, en el caso del Che" (Prenz, s/d8). Aparece la espada de Quijote y el habano del Che traídos por un tercer personaje. Dentro de la estructura de Ernesto Guevara guerrillero Alsina introduce la boina, y en el caso de Don Quijote el yelmo de oro de Mambrino. Otro elemento más es La Poderosa II y Rocinante.

DON QUIJOTE: iAlto! Que no hay razón para que Caballero tan famoso inicie este viaje de aventuras caminando. Y más aún si debe llegar tan lejos. (Silba y luego grita.) iRocinante!

(Entra Ella con una moto.)

CHE: iLa Poderosa II, la moto de mis viajes por Sudamérica! (Alsina, 2012:10)

Alsina vincula a Rocinante con La Poderosa amparado en los materiales de archivo a los que podía referir. Existen registros sobre la vida del Che donde se señala que Guevara leía el libro de Cervantes: "El Ernestito que también leía el Don Quijote, ya convertido en el Che, muchos años después escribirá a sus padres, despidiéndose antes de una de sus epopeyas: $<$ Queridos viejos: Otra vez siento bajo mis talones el costillar de Rocinante, vuelvo al camino con mi adarga al brazo>"(O'Donell, 2012: 30).

A su vez, como nota de color deberíamos sumar que Alsina mismo había sido inspirado por la figura del Quijote desde su ingreso a las artes teatrales:

En cuánto al Quijote creo que hago teatro por algo que tiene que ver son su figura. Cuando tenía 12 o 13 años vi una obra teatral "El Hombre de la Mancha”, en Tucumán, representada por el elenco universitario y me conmoví profundamente. Me di cuenta, tan temprano, qué era lo que yo deseaba para mi vida: hacer teatro. La figura del Quijote, su idealismo, su lucha por una utopía idealista, me abrazó. Y fue a través de aquella

${ }^{8}$ Disponible en www.carlosalsina.com/estudioc.htm 
experiencia inicial que supe hacia adónde quería dirigir mi vida. A veces digo que nunca más me levanté de esa butaca y que todavía estoy allí, soñando, y que estas palabras que le escribo, no son más que un sueño, como lo es (tal vez) toda mi vida. Quizás, desde aquella butaca del Teatro Alberdi, sigo soñando todo lo que me pasó después. En el secundario empecé a hacer teatro (me recibí de bachiller en 1977) y leí en la cátedra de Literatura el "Don Quijote". Me enamoré de la novela y la leí con atención, ya entonces. Luego, a través de los años, la releí algunas veces. (Alsina, entrevista realizada el 13 de junio de 2017)

\section{Guevara en el teatro: entre la memoria histórica y una lectura presente}

Retomando el contexto de los años noventa podemos observar que la obra cuestiona el ser o no ser Che Guevara, el ser o no ser solo mito constituido en personaje histórico. Alsina con ironía hace jugar al Quijote y al Che un mismo camino. Estos personajes tratan de salir de allí hasta que encuentran la respuesta al dejar de lado el carácter de mitos.

CHE: "Unos fueron y ya no son. Otros son y no fueron”. ¿Te das cuenta? DON QUIJOTE: ¿De qué? (Avanza a repetir lo conocido.)

CHE: iEsperá! ¿Y si dejáramos por un momento el peso de lo que fuimos?

(...) CHE: iIntentemos escapar de nuestros propios mitos! iAsí tal vez podamos romper el círculo! (Alsina, 2012: 21)

En este punto Mircea Eliade explica que "la memoria popular aplica una articulación y una interpretación completamente análogas a los acontecimientos y a los personajes históricos" (Eliade, 2006, 53), y agrega una observación interesante en la que expone que el hombre moderno se quiere y se sabe como creador de la historia, a diferencia del hombre de las civilizaciones tradicionales que poseían una visión negativa de la historia (Eliade, 2006). Juntar al Quijote con Guevara es unir esas dos ideas de la historia: la del Quijote anclada en la ficción, la de Guevara reescrita y reinterpretada a lo largo de las reelaboraciones del hombre histórico.

Perla Zayas de Lima señala diversas definiciones de mito sobre el líder político. Ella observa también una serie de divorcios entre la figura real y la que se ve del líder. Así refiere aplicando a Guevara: 
el líder como figura sociopolítica "provoca una escisión entre la persona real que es y el tipo que origina" (Labourdette, 1987, 138). Es la figura que hace olvidar a los hombres el texto que han ido a escuchar (Sennet, 1978) (...) o que tiene el mérito de "hacer verosímil un discurso que carece de referentes exteriores de verosimilitud” (Rinesi, 1994, 107), lo que es aplicable al Che. (Zayas de Lima, 2010: 195)

Nos parece pertinente agregar que Alsina juega con esta idea de mito de una manera más amplia. Este autor reconoce que si el personaje de Guevara permanece en su papel, lo revolucionario decanta en acto de habla; o en términos de Roland Barthes (2004) en mito de izquierda.

Alsina señalaba que: iLadran Che! "signifique tirar las cartas de juego nuevamente, esto sin perder el sentido de las utopías, pero descubriendo cuáles pueden ser las nuevas aventuras de estos dos personajes. En esta obra intento mostrar un proceso de desmitificación de ellos mismos para poder seguir siendo" (Tossi, 2004). Si bien esto funciona con algunos puntos señalados, Alsina construye mitos a través del lenguaje artístico que elige producir. Desde allí narra el diálogo y el juego entre el guerrillero y el caballero andante que se disputan sobre cómo perpetuar la utopía; la misma utopía que proclaman cumplida Sancho y Camilo desde sus cartas. El autor construye mito, en sentido barthesiano, desde la comedia y lo hace con conciencia del fenómeno que se produce: el cuestionamiento entre lo verosímil y la historia, un fenómeno que el propio Cervantes plantea a modo de pregunta en el capítulo XLVIII del Quijote I

“(...) ¿cómo es posible que satisfaga a ningún mediano entendimiento que, fingiendo una acción que pasa en tiempo del Rey Pepino y Carlomagno, el mismo que en ella hace la persona principal le atribuyan que fue el emperador Heraclio, que entró con la Cruz en Jerusalen, y el que ganó la Casa Santa, como Godofre de Bullon, habiendo infinitos años de lo uno a lo otro; y fundándose la comedia sobre cosa fingida, atribuirle verdades de historia y mezclarle pedazos de otras cosas sucedidas a diferentes personas y tiempos, y esto, no con trazas verosímiles, si no con patentes errores de todo punto inexcusables?" (2010: 478)

Este sentido, la construcción de mito de la obra se ampara en su práctica intertextual. Esto lo vemos en tanto que, tal como plantea Grisby Ogas Pugas, quien devele esos intertextos deberá responder a la idea de un tipo 
de lector modelo. Dirá Ogas Pugas: "la condición de producción del intertexto, las estrategias propuestas prevén también el movimiento del otro (...)" (2014: 81). Por lo que la obra de Alsina la decodificaría "un lector con capacidad mnemónica y asociativa especial y una enciclopedia en la que prevalezca una competencia intertextual que le permita, al tiempo que realiza la lectura lineal, efectuar las lecturas oblicuas" (Ogas Pugas, 2014: 8182).

\section{Conclusiones}

A lo largo del artículo pudimos desarrollar un trabajo comparativo que dio cuenta de los intertextos utilizados en la obra iLadran Che! de Carlos Alsina. En aquellos observamos la incorporación específica de determinados apartados sobre el Quijote de Cervantes y los registros de la vida del Che basados en los diarios y su biografía. La intención de detectar este cruce de registros históricos y de ficción nos fue funcional para comprender cómo se construye desde la óptica de este creador la imagen de Guevara. Así percibimos y analizamos cómo se lo compuso como héroe guerrillero y cómo se mostraron los mitos que lo atravesaron. A su vez, la obra y su creador aportaron sobre ello una mirada desde el presente, que tenía como meta realizar una crítica sobre el contexto histórico en que fue escrita y puesta en escena. El neoliberalismo en el gobierno menemista y la caída de los grandes discursos (con el suceso del muro de Berlín y la disolución de la URSS) provocaron en Alsina el puntapié para pensar la imagen de Guevara, vaciada de sentido político por aquella época. Esto dio por resultado que el acto de llevar a escena una imagen como el Che produjo una acción memorial sobre la figura, que entrelazada a un personaje literario construyó un mundo en el que los hechos históricos se remarcaron bajo la función poética de la ficción. Parte de la función poética que se le agrega a la historia del Che (de la realidad) estuvo dada por el mecanismo intertextual que se generó en el diálogo con su biografía y su diario de viaje. Asimismo, la intertextualidad también aportó, tal como vimos, una interacción ficcional entre el personaje histórico y Don Quijote. Esto último brindó nuevas lecturas sobre la novela y la realidad histórica desde el presente descripto. Estas lecturas fueron múltiples e inacabadas en tanto que dentro del fe- 
nómeno de lo intertextual, la recepción se encuentra frente al desafío de estar alerta u omitir por ejemplo los vínculos señalados a lo largo de este artículo.

\section{Referencias}

Alsina, C. (2012), iLadran Che!. En Celcit Dramática Latinoamericana 381, Buenos Aires, Argentina: Celcit.

Baczko, B. (1991). Los imaginarios sociales. Memorias y esperanzas colectivas. Buenos Aires, Argentina: Nueva Visión.

Bajtin, M. (1999). Estética de la creación verbal. México: s.XXI.

Barthes, R. (2004). Mitologías. Buenos Aires: Siglo XXI.

Casalduero, J. (1974). Sentido y forma del teatro de Cervantes. Madrid, España: Editorial Gredos.

. (1981). Estudios sobre el teatro español. Madrid, España: Editorial Gredos.

De Cervantes, M. (2010). Don Quijote de la Mancha. España: Editorial Planeta DeAgostini.

Dubatti, J. (s/f). "El teatro de Carlos Alsina". Disponible en: http://www. carlosalsina.com/estudioc.htm

Eliade, M. (2006). El mito del eterno retorno. Buenos Aires, Argentina: Emecé.

Guevara, E. (2012). Notas de viaje. Diarios de motocicleta. S/f: Ocean Sur.

Kristeva, J. (1969). "La palabra, el diálogo y la novela”. En Semiótica, 1, Barcelona, España: Fundamentos.

O’Donell, M. (2012). Che: el argentino que quiso cambiar el mundo. Buenos Aires, Argentina: Sudamericana.

Ogas Pugas, G. (2014). "Teatro e intertextualidad: la fórmula contra el olvido. Recepción productiva, apropiación e intertexto en el teatro argentino moderno". En Telón de fondo, 20 de diciembre, Buenos Aires, Argentina. Disponible en: www.telondefondo.org

Pérez Firmat, G. (1978). "Apuntes para un modelo de la intertextualidad en literatura”. En Romanic Review, LXIX, No 1-2 (January-March), p. 1-14. New York, Estados Unidos: Columbia University.

Prenz, A. C. (s/f). "Ladran Che! Una conversación latinoamericana de Don 
Quijote y otras reflexiones sobre el teatro". Universidad de Trieste. Disponible en: http://www.carlosalsina.com/estudioc.htm

Tossi, M. (2004). "El teatro como arqueología del presente". En Cuadernos del Picadero, Cuaderno $\mathrm{N}^{\mathrm{O}} 2$-Instituto N. de Teatro, enero, 2004. Disponible en: http://www.teatrodelpueblo.org.ar/sobretodo/o2_entrevistas/tossioo1.htm

Zayas de Lima, P. (2010). El universo mítico de los argentinos en escena. Buenos Aires, Argentina: INT. 